\title{
BMJ Open Legacy effects of statins on cardiovascular and all-cause mortality: a meta-analysis
}

\author{
Agnish Nayak, ${ }^{1}$ Andrew Hayen, ${ }^{2}$ Lin Zhu, ${ }^{2}$ Kevin McGeechan, ${ }^{3}$ Paul Glasziou, ${ }^{4}$ \\ Les Irwig, ${ }^{3}$ Jenny Doust, ${ }^{4}$ Gabriel Gregory, ${ }^{5}$ Katy Bell ${ }^{3}$
}

To cite: Nayak A, Hayen A, Zhu L, et al. Legacy effects of statins on cardiovascular and all-cause mortality: a meta-analysis. BMJ Open 2018;8:e020584. doi:10.1136/ bmjopen-2017-020584

- Prepublication history and additional material for this paper are available online. To view these files, please visit the journal online (http://dx.doi. org/10.1136/bmjopen-2017020584).

Received 10 November 2017 Revised 18 May 2018 Accepted 31 July 2018

Check for updates

(c) Author(s) (or their employer(s)) 2018. Re-use permitted under CC BY-NC. No commercial re-use. See rights and permissions. Published by BMJ.

1 UNSW Medicine, University of New South Wales, Sydney, New South Wales, Australia

${ }^{2}$ Australian Centre for Public and Population Health Research, University of Technology Sydney, Sydney, New South Wales,

Australia

${ }^{3}$ University of Sydney School of Public Health, The University of Sydney, Sydney, New South Wales, Australia

${ }^{4}$ Centre for Research in Evidence Based Practice, Bond University, Gold Coast, Queensland,

Australia

${ }^{5}$ The University of Sydney School of Medicine, The University of Sydney, Sydney, New South Wales, Australia

Correspondence to

Dr Katy Bell;

katy.bell@sydney.edu.au

\section{ABSTRACT}

Objectives To assess evidence for 'legacy' (post-trial) effects on cardiovascular disease (CVD) mortality and all-cause mortality among adult participants of placebocontrolled randomised controlled trials (RCTs) of statins. Design Meta-analysis of aggregate data.

Setting/Participants Placebo-controlled statin RCTS for primary and secondary CVD prevention.

Methods Data sources: PubMed, Embase from inception and forward citations of Cholesterol Treatment Trialists' Collaborators RCTs to 16 June 2016. Study selection: Two independent reviewers identified all statin RCT follow-up reports including $\geq 1000$ participants, and cardiovascular and all-cause mortality. Data extraction and synthesis: Two independent reviewers extracted data in accordance with the Preferred Reporting Items for Systematic Reviews and Meta-Analyses guidelines. Main outcomes: Post-trial CVD and all-cause mortality.

Results We included eight trials, with mean post-trial follow-up ranging from 1.6 to 15.1 years, and including 13781 post-trial deaths (6685 CVD). Direct effects of statins within trials were greater than legacy effects posttrials. The pooled data from all eight studies showed no evidence overall of legacy effects on CVD mortality, but some evidence of legacy effects on all-cause mortality $(p=0.01)$. Exploratory subgroup analysis found possible differences in legacy effect for primary prevention trials compared with secondary prevention trials for both CVD mortality $(p=0.15)$ and all-cause mortality $(p=0.02)$. Pooled post-trial HR for the three primary prevention studies demonstrated possible post-trial legacy effects on CVD mortality ( $\mathrm{HR}=0.87 ; 95 \% \mathrm{Cl} 0.79$ to 0.95$)$ and on all-cause mortality ( $\mathrm{HR}=0.90 ; 95 \% \mathrm{Cl} 0.85$ to 0.96 ).

Conclusions Possible post-trial statin legacy effects on all-cause mortality appear to be driven by the primary prevention studies. Although these relative benefits were smaller than those observed within the trial, the absolute benefits may be similar for the two time periods. Analysis of individual patient data from follow-up studies after placebo-controlled statin RCTs in lower-risk populations may provide more definitive evidence on whether early treatment of subclinical atherosclerosis is likely to be beneficial.

\section{INTRODUCTION}

'Legacy effects' are treatment effects that persist or emerge at some time after trial

\section{Strengths and limitations of this study}

- Our sensitive search strategy means this study is likely to have included all follow-up reports of the major placebo-controlled statin trials, including recent follow-up reports for two of the studies (WOSCOPS and LIPID).

- We focus analysis on the post-trial period which is best for detection of legacy effects.

- However, post-trial data are no longer a randomised comparison, and legacy effects may be larger than we estimated.

- The main limitation is that our findings are based on aggregate data, and we did not have information on whether or not an individual was treated with statins during the post-trial period, and for how long, as well as their cardiovascular risk factor levels and other potential confounders.

treatment ends. The existence, or not, of such legacy effects have important clinical implications, including the potential value of starting preventative treatment at a younger age, and the risks of treatment cessation. Although technically even short-term or transient improvement or worsening of symptoms and signs may be classified as a legacy effect, most people appear to use the term to indicate sustained clinical benefit or harm. ${ }^{1-7}$ Legacy effects have been explained as the "memory of a treatment given in an early phase of a disease which produces benefits long after the cessation of intervention'. ${ }^{2}$ They are an extension of the belief that we should intervene with treatment early on in the course of a chronic disease/condition; the legacy effect assumes that the duration of the condition predicts permanent pathological changes which in turn are strong modifiers of treatment effectiveness.

Recently, there has been considerable interest in the possible legacy effects of statins, ${ }^{8} 9$ sparked by reports on the longterm outcomes for participants of large placebo-controlled trials. In some of these 


\section{Box 1 Search terms for Medline Search}

1. Follow-Up Studies/

2. random $\$ . t w$

3. placebo.tw

4. Hydroxymethylglutaryl-CoA Reductase Inhibitors/

5. cholesterol/

6. lipids/

7. (\#1) AND (\#2) AND (\#3) AND (\#4 OR \#5 OR \#6).

reports, ${ }^{410}$ there is still a persistent survival advantage to participants who were randomised to statin during the trial, even though there was no or minimal difference in the management of participants after the trial ended. Legacy effects could indicate that earlier treatment with statins slows atherosclerotic plaque build-up in arteries and so alters the natural disease progression during a person's lifetime. As with the direct effects of statins, these legacy effects may be pleiotropic, and act through anti-inflammation, anticoagulation and/or lipid lowering. This hypothesis has some support from the finding that statins have minimal effect on cardiovascular disease (CVD) prevention in patients with advanced kidney disease who require haemodialysis, and who have high short-term risk of CVD, ${ }^{11}$ but reduce CVD events in patients with earlier chronic kidney disease who are not yet requiring haemodialysis. ${ }^{12}$ There are also some data from a small imaging study of patients with angina to support the early treatment hypothesis, where similar reduction in lipid levels appeared to result in reduction in plaque volume only in participants younger than 65 years. ${ }^{13}$ Finally, differences in long-term response to statins are noted for primary prevention trials compared with secondary prevention trials. ${ }^{14}$ To this end, aggressive lipid-lowering therapy in much younger individuals with lower risk for CVD has been suggested as a possible means of primary prevention. Some have argued for universal screening of cholesterol levels in young people and offering early statin treatment to those with raised levels, ${ }^{15-17}$ whereas others have argued that statins be offered to all young people, regardless of cholesterol levels. ${ }^{518}$

At least some of the survival benefit observed on longterm follow-up is attributable to the direct treatment effects on CVD outcomes observed during the within-trial period. To illustrate this point, we generated data to simulate the situation where there was a legacy effect (see online supplementary eFigure $1 \mathrm{~A}$ and $1 \mathrm{~B}$ ), and where there was not a legacy effect (online supplementary eFigure 1C and 1D). We simulated two scenarios where an intervention has effects during the trial period, and either (1) has an additional effect after the trial (legacy effect) or (2) has no additional effect after the trial (no legacy effect). In the survival curves of both scenarios, the apparent legacy effect is exaggerated because the cumulative incidence includes the direct effects during the initial trial period (see online supplementary eFigure 1A and 1C). If hazard curves are constructed instead, the direct effects during the initial trial period are not included in the instantaneous hazard of the post-trial periods, allowing an unbiased estimation of the legacy effect (see online supplementary eFigure 1B and 1D; note that these are curves of the instantaneous hazard at each time point, and are not curves of hazard ratios (HRs). Details of the methods for the simulation are provided in the Appendix). Although survival curves like online supplementary eFigure $1 \mathrm{~A}$ and $1 \mathrm{C}$ demonstrate that the direct effects of the intervention (observed during the trial period) are still apparent many years later, they do not provide evidence of legacy effects after the intervention has ceased. From the hazard curves in online supplementary eFigure $1 \mathrm{~B}$ and $1 \mathrm{D}$, it is clear that to estimate legacy effects, we should instead focus on outcomes observed during the post-trial period. To this end, we aimed to identify and combine estimates of the effect of trial treatment group allocation on post-trial all-cause and CVD mortality from published reports on the long-term follow-up after placebo-controlled trials of statins.

\section{METHODS}

\section{Protocol and registration}

The review protocol was not registered.

\section{Selection}

We performed a systematic search and meta-analysis of all reports on follow-up after randomised, placebo-controlled studies of adults (age $>18$ years) of statins with $\geq 1000$ participants. As the legacy effect relates to the difference in treatment received within the trial period, we focused our analysis on follow-up reports of high-quality, large randomised controlled trials (RCTs). We chose to limit our studies to those with $\geq 1000$ participants in the original trial for consistency with the Cholesterol Treatment Trialists' Collaboration. These large trials were designed to assess effects on mortality within the trial period, and their follow-up reports are the most appropriate studies to address post-trial effects on mortality. We excluded studies that did not report mortality data during posttrial follow-up. The primary outcomes were death due to all-causes and death due to CVD.

\section{Search strategy}

We identified placebo-controlled RCTs of cholesterol-lowering treatment from the Cholesterol Treatment Trialists' Collaboration ${ }^{19}$ and ran forward citation searches in Scopus; our search was limited to those citations which included one of the investigators from the RCT. We searched for additional reports in Medline and Embase with no earliest date restriction, though to 16 June 2016 using the terms listed in box 1 , with no restrictions on year published, type of publication or language. We checked references of included studies to identify further relevant papers and contacted trialists to identify updated or additional reports. 


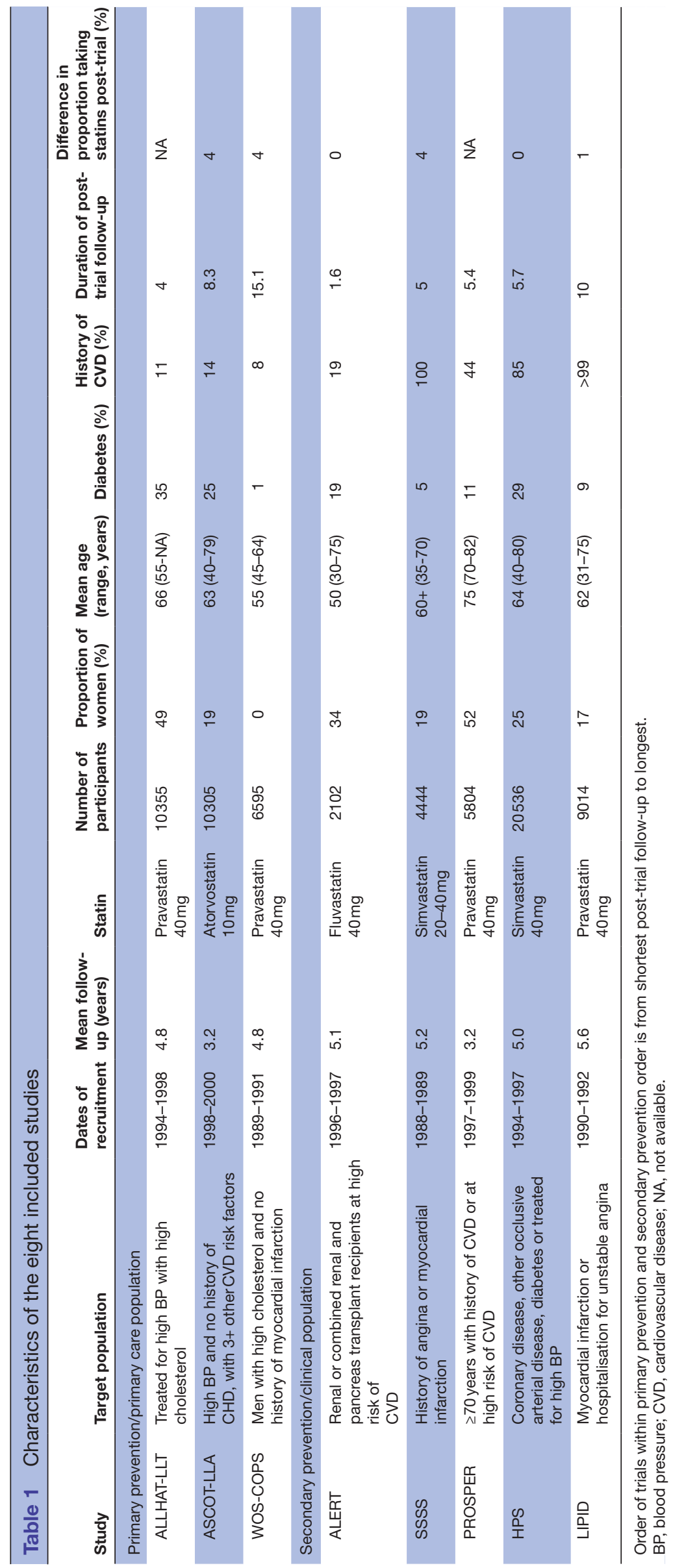

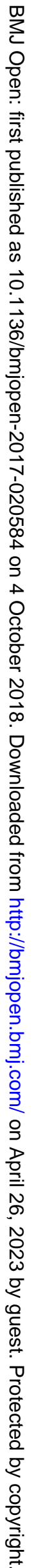




\begin{tabular}{lll}
$\begin{array}{l}\text { Study (Initial Year of } \\
\text { Randomisation) }\end{array}$ & \multicolumn{2}{c}{ n (events) } \\
& Active & Placebo \\
ALLHAT-LLT (1994) & & \\
Within-trial & & \\
Post-trial & $5089(529)$ & $5110(546)$ \\
ASCOT-LLA (1998) & $4428(484)$ & $4432(511)$ \\
Within-trial & & \\
Post-trial & $5168(74)$ & $5137(82)$ \\
WOSCOPS (1989) & $2234(377)$ & $2198(430)$ \\
Within-trial & & \\
Post-trial & $3302(49)$ & $3293(71)$ \\
ALERT (1996) & $3196(364)$ & $3158(423)$ \\
Within-trial & & \\
Post-trial & $1050(66)$ & $1052(73)$ \\
SSSS (1988) & $819(22)$ & $833(25)$ \\
Within-trial & & \\
Post-trial & & \\
PROSPER (1997) & $2221(136)$ & $2223(207)$ \\
Within-trial & $2039(155)$ & $1967(128)$ \\
Post-trial & & \\
HPS (1994) & $2891(122)$ & $2913(154)$ \\
Within-trial & $2588(396)$ & $2600(375)$ \\
Post-trial & & \\
LIPID (1990) \\
Within-trial \\
Post-trial
\end{tabular}
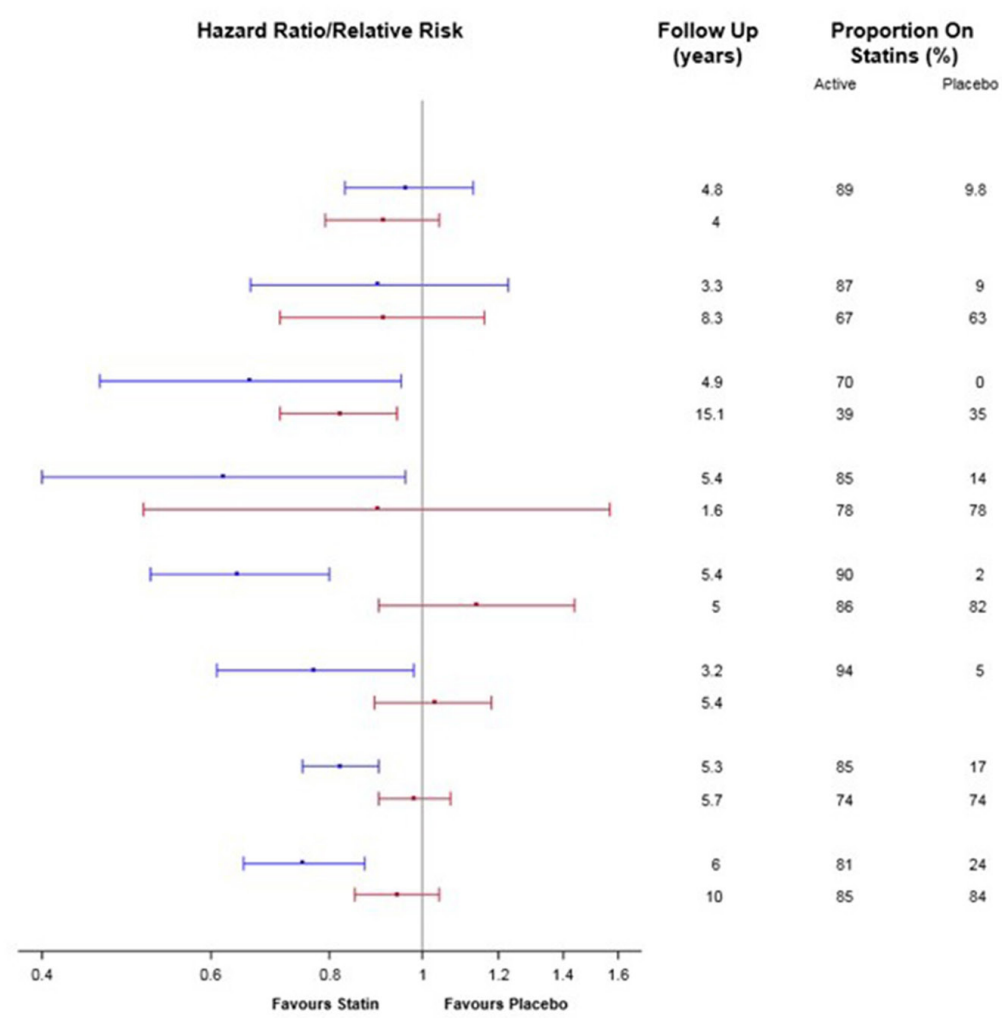

Figure 1 Direct (within-trial) and legacy (post-trial) effects of statins on cardiovascular disease mortality for eight trials. Note: Within primary and secondary prevention subgroups, studies are ordered by duration of follow-up.

\begin{tabular}{|c|c|c|}
\hline \multirow{2}{*}{$\begin{array}{l}\text { Study (Initial Year of } \\
\text { Randomisation) }\end{array}$} & \multicolumn{2}{|c|}{ n (events) } \\
\hline & Active & Placebo \\
\hline \multicolumn{3}{|l|}{ ALLHAT-LLT (1994) } \\
\hline Within.trial & $5089(661)$ & $5110(678)$ \\
\hline Post-trial & $4428(897)$ & $4432(948)$ \\
\hline \multicolumn{3}{|l|}{ ASCOT-LLA (1998) } \\
\hline Within-trial & $5168(185)$ & $5137(212)$ \\
\hline Post-trial & $2234(377)$ & $2198(430)$ \\
\hline \multicolumn{3}{|l|}{ woscops (1989) } \\
\hline Within-trial & $3302(106)$ & $3293(135)$ \\
\hline Post-trial & $3196(1036)$ & $3158(1117)$ \\
\hline \multicolumn{3}{|l|}{ ALERT (1996) } \\
\hline Within-trial & $1050(143)$ & $1052(138)$ \\
\hline Post-trial & $819(51)$ & $833(51)$ \\
\hline \multicolumn{3}{|l|}{ SSSS (1988) } \\
\hline Within-trial & $2221(182)$ & $2223(256)$ \\
\hline Post-trial & $2039(232)$ & $1967(212)$ \\
\hline \multicolumn{3}{|l|}{ PROSPER (1997) } \\
\hline Wathin-trial & $2891(298)$ & $2913(306)$ \\
\hline Post-trial & $2588(931)$ & $2600(928)$ \\
\hline \multicolumn{3}{|l|}{ HPS (1994) } \\
\hline Within-trial & $10269(1328)$ & $10267(1507)$ \\
\hline Post-trial & $8863(1962)$ & $8656(1949)$ \\
\hline \multicolumn{3}{|l|}{ LIPID (1990) } \\
\hline Within-trial & $4512(498)$ & $4502(633)$ \\
\hline Post-trial & $3932(1341)$ & $3789(1319)$ \\
\hline
\end{tabular}
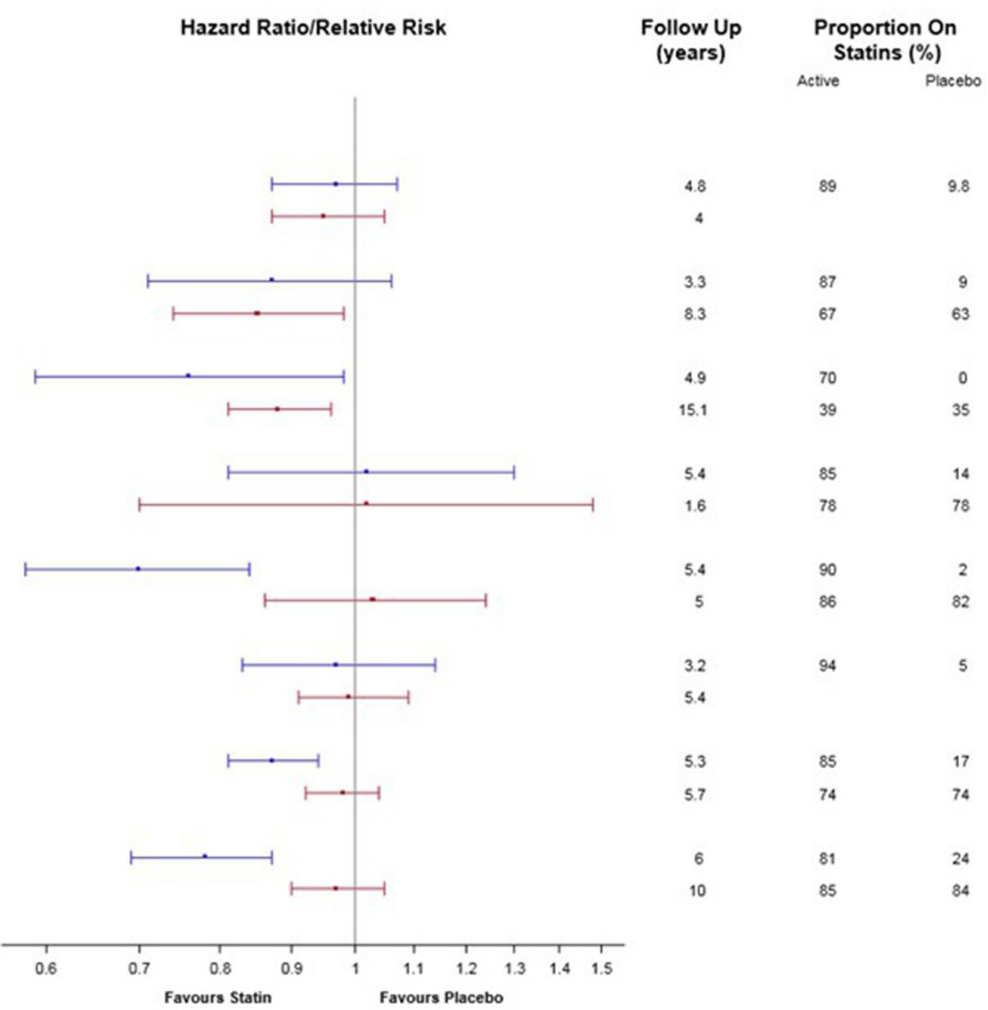

Figure 2 Direct (within-trial) and legacy (post-trial) effects of statins on all-cause mortality for eight trials. Note: Within primary and secondary prevention subgroups, studies are ordered by duration of follow-up. 


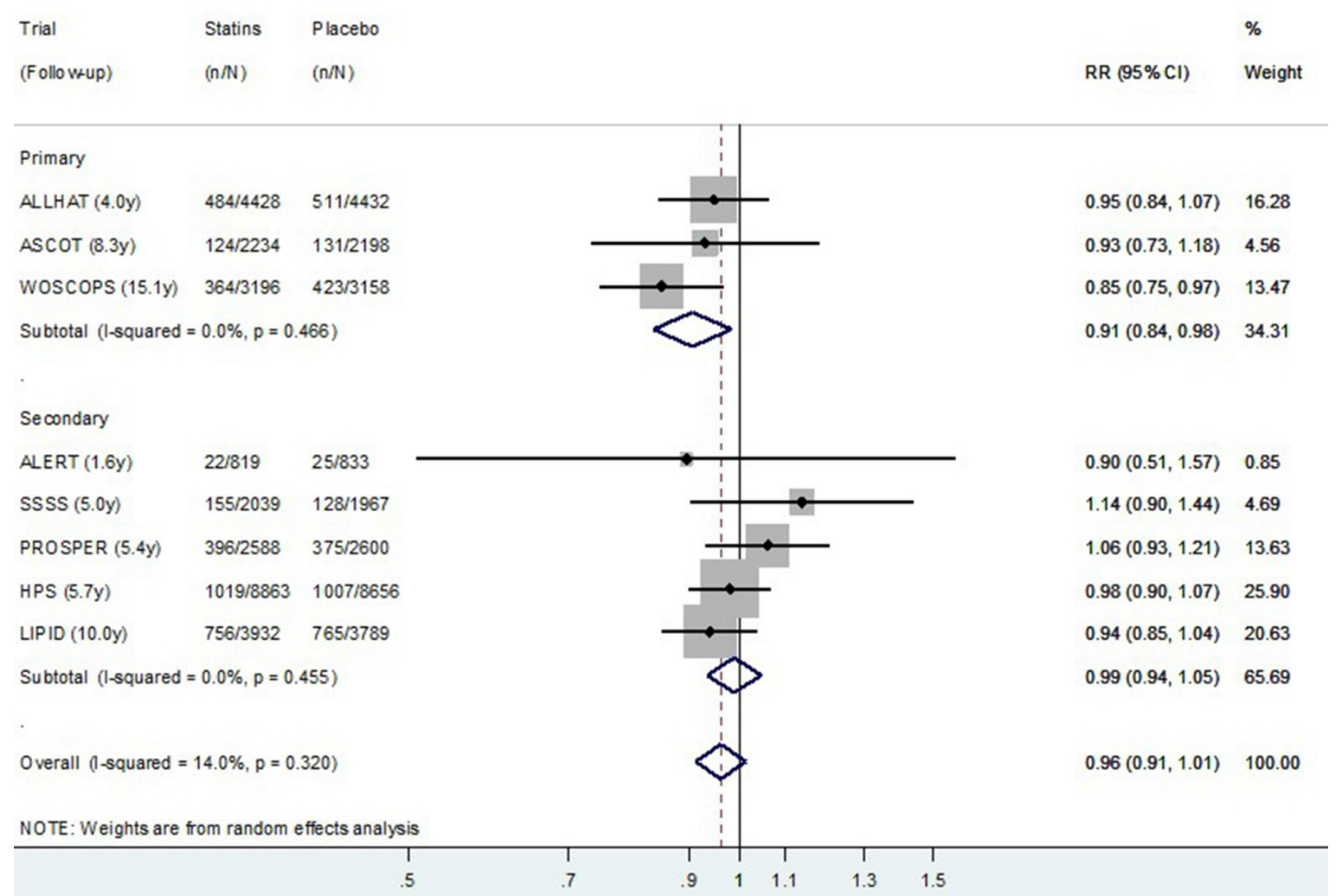

Figure 3 Random effects meta-analysis of relative risks for legacy (post-trial) effects of statins on cardiovascular disease mortality for eight trials. Note: Within primary and secondary prevention subgroups, studies are ordered by duration of followup. RR, relative risk.

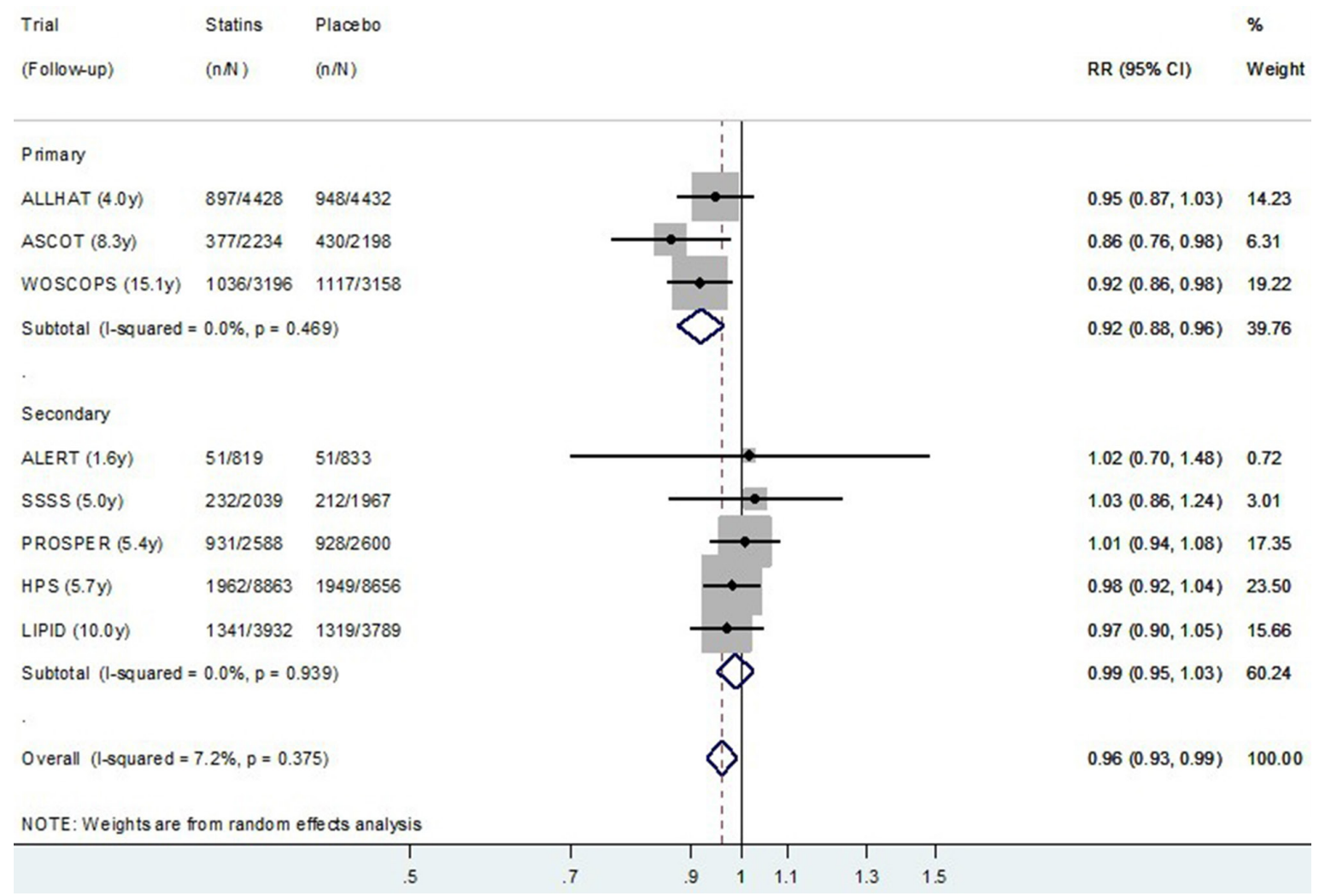

Figure 4 Random effects meta-analysis of relative risks for legacy (post-trial) effects of statins on all-cause mortality for eight trials. Note: Within primary and secondary prevention subgroups, studies are ordered by duration of follow-up. RR, relative risk. 


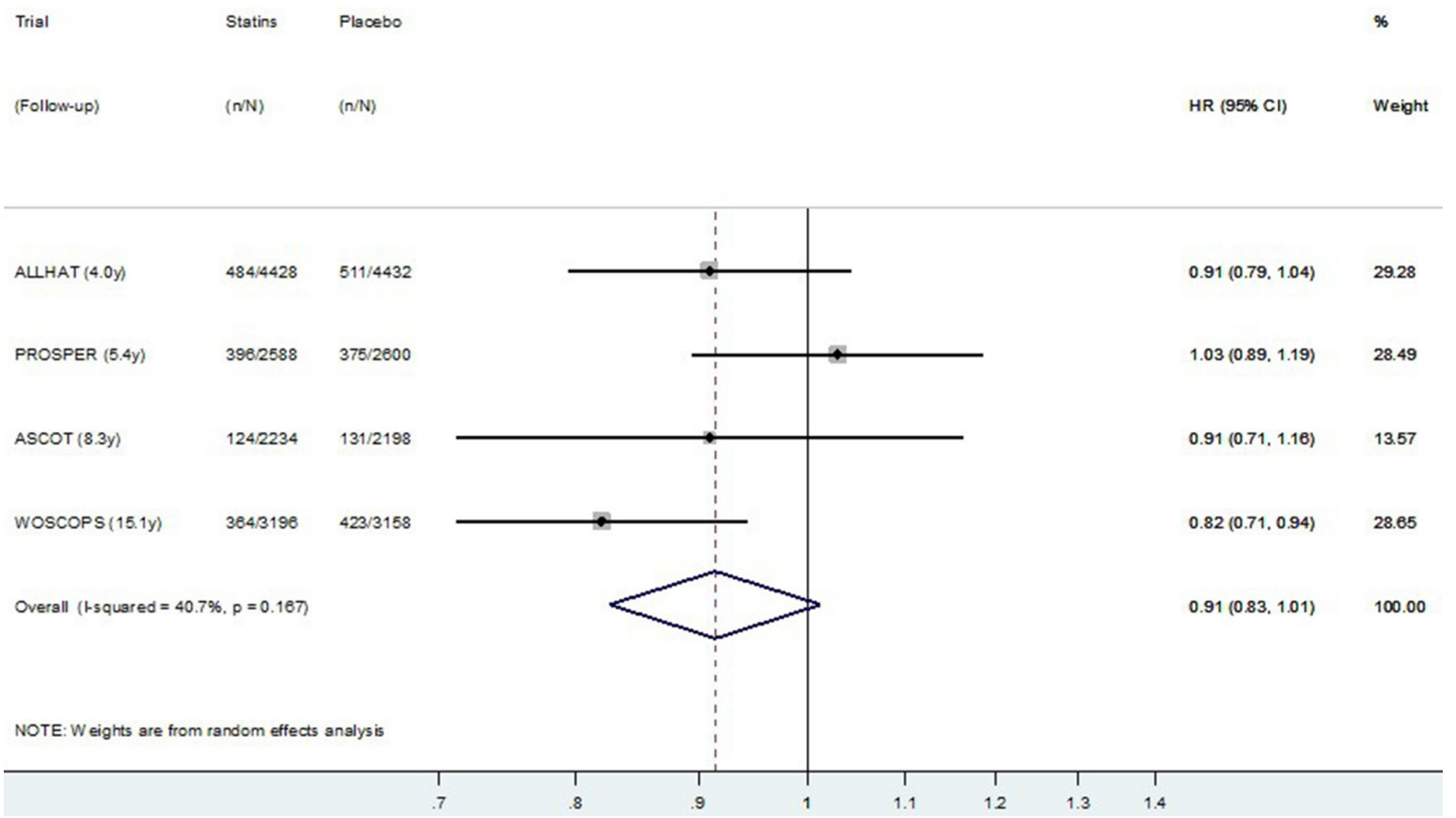

Figure 5 Random effects meta-analysis of HR for legacy (post-trial) effects of statins on cardiovascular disease mortality for four trials. Note: Within primary and secondary prevention subgroups, studies are ordered by duration of follow-up.

\section{Validity assessment}

Two authors (AN and LZ) extracted data on the following characteristics which may bias the estimated legacy effect: mean follow-up (years) and difference in proportion taking statins. Data were extracted separately for the within trial and post trial periods for each study.

\section{Study selection and data abstraction}

Two authors (AN and KB) independently checked the titles and abstracts of all citations identified through the database searches and forward citation search. Full text was obtained if either author judged the article potentially relevant. The same two authors then independently checked all the full-text articles for eligibility, resolving disagreements through discussion.

Two authors independently extracted clinical data (AN and LZ) using standardised forms, deciding disagreements through discussion with a third author $(\mathrm{KB})$. We did not calculate formal measures of agreement to describe agreement between reviewers. The Cochrane Collaboration recommends against doing this, and instead recommends exploring reasons for any disagreement early on in the review process,${ }^{20}$ which we did through discussion.

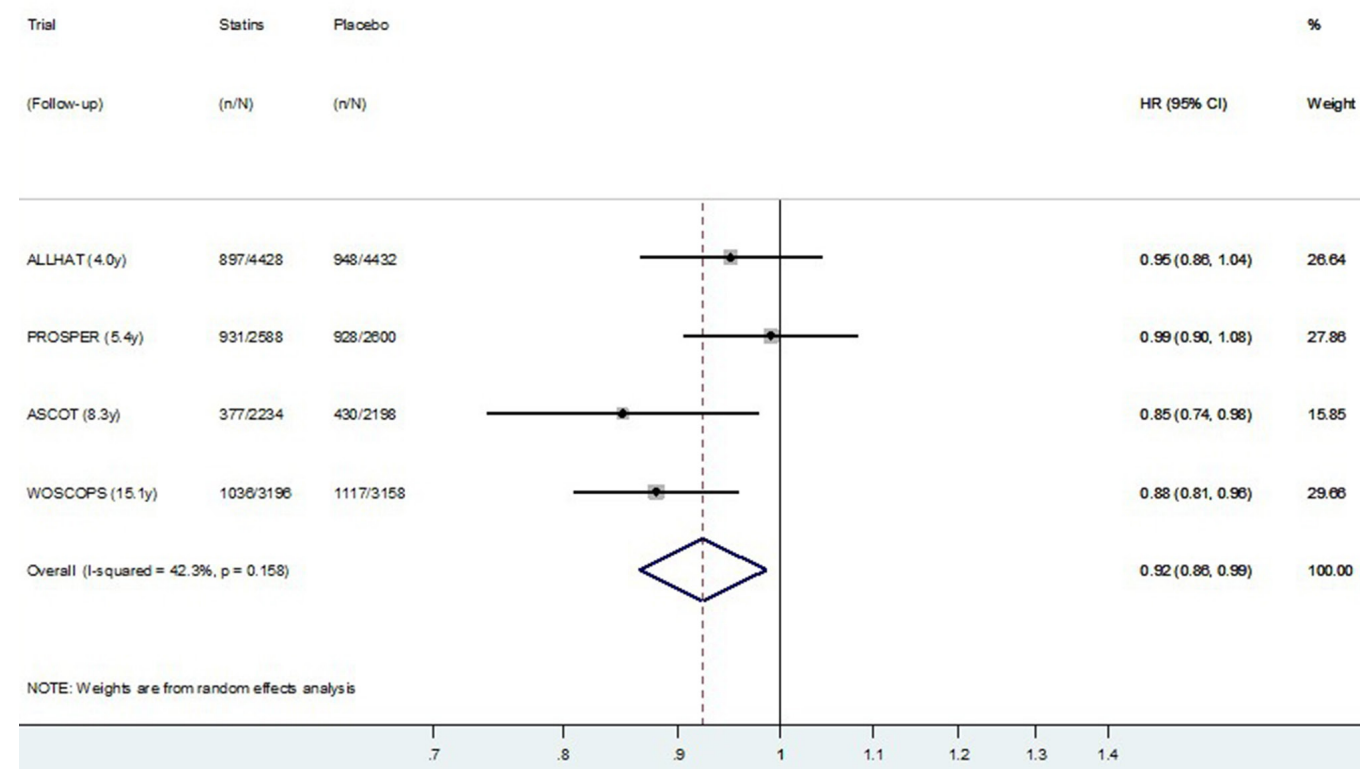

Figure 6 Random effects meta-analysis of HR for legacy (post-trial) effects of statins on all-cause mortality for four trials. Note: Within primary and secondary prevention subgroups, studies are ordered by duration of follow-up. 


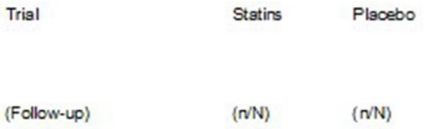

$\%$

(rollowup) $(\mathrm{nN}) \quad(\mathrm{N})$

HR $(95 \% \mathrm{Cl}) \quad$ Weight

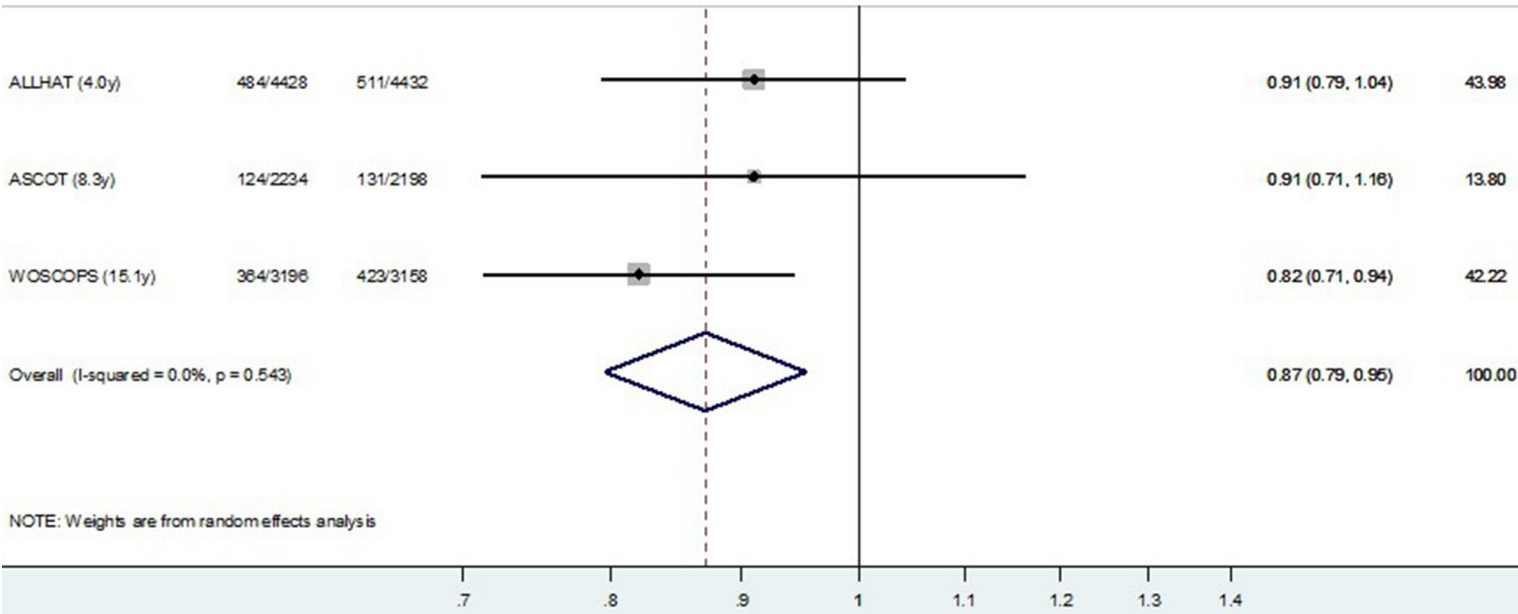

Figure 7 Random effects meta-analysis of HR for legacy (post-trial) effects of statins on cardiovascular disease mortality for three primary prevention trials. Note: Within primary and secondary prevention subgroups, Studies are ordered by duration of follow-up.

We extracted separate data on all-cause mortality and CVD-specific mortality for the within-trial and post-trial periods; the number of people at risk of each type of event at the start of the trial and at the start of the posttrial follow-up; the proportion of people taking statins within trial and post-trial; and the duration of follow-up within trial and post-trial. We attempted to extract differences in mean total cholesterol, but these were missing for at least one of the periods in the majority of studies. Further data on the original trials were obtained from Cholesterol Treatment Trialists Collaboration (CTTC). ${ }^{21}$

\section{Statistical methods}

Summary statistics and plots for individual trials were generated using SAS V.9.4.

Meta-analytic models of post-trial data were built using STATA (V.14.2).

We built meta-analytic models for CVD mortality and all-cause mortality using reported number of events and number at risk for the post-trial period. Our principal summary measures for the models were relative risk and HR. We used adjusted relative risks where these were

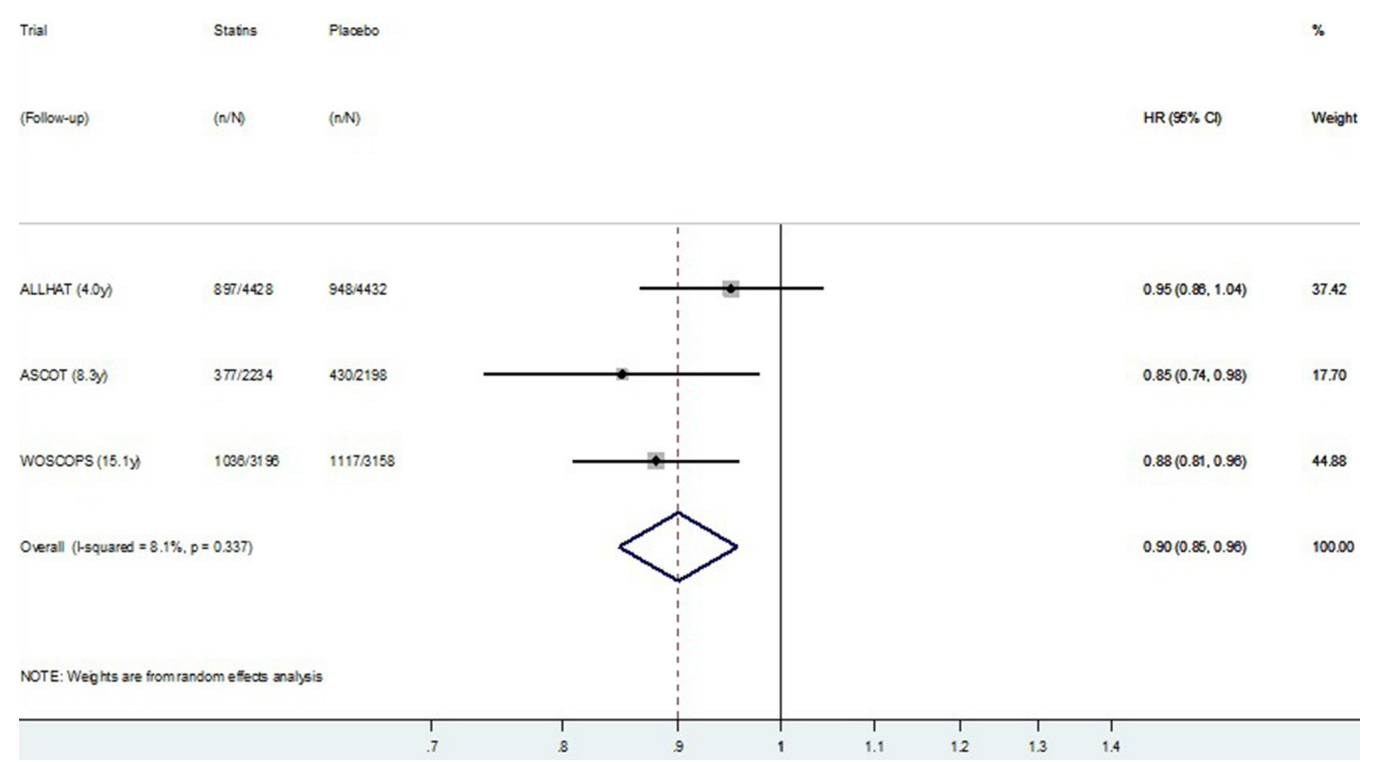

Figure 8 Random effects meta-analysis of HR for legacy (post-trial) effects of statins on all-cause mortality for three primary prevention trials. Note: Within primary and secondary prevention subgroups, Studies are ordered by duration of follow-up. 
reported, and calculated unadjusted relative risks where they were not. We built random effects models for the analysis. We assessed the hetereogeneity of results using visual inspection of forest plots and $\mathrm{I}^{2}$ statistics, and we conducted exploratory subgroup analysis using meta-regression to compare primary and secondary prevention trials. For the subgroup analysis, we tested for subgroup differences using a permutation test with 1000 permutations. $^{22}$

We also built HR meta-analytic models for CVD mortality and all-cause mortality where these were reported in the primary studies. We undertook sensitivity analysis by restricting the model to primary prevention trials.

\section{Patient and public involvement}

Patients and or public were not involved in this meta-analysis of published data.

\section{RESULTS}

We identified 21 placebo-controlled RCTs of statins included in the CTTC for forward citation searching ${ }^{23-43}$ which retrieved 1520 abstracts (restricting search to reports which included an original trialist as an author). We identified a further 828 abstracts from Medline and Embase (searches to 16 June 2016), and after excluding duplicates, 1520 titles and abstracts were screened. We retrieved 61 papers for full-text review, 47 of which did not meet our selection criteria (see online supplementary eFigure 2). Reference searching of the remaining 14 studies identified one further study. Seven of the 15 studies used overlapping data: for each set of potentially overlapping reports, we chose the most recent report. This resulted in eight studies finally included in our review (table 1 ).

The original RCTs ranged in mean duration from 3.2 to 5.2 years, included trials of simvastatin, pravastatin, fluvastatin and atorvastatin, and their primary results were published between 1994 and 2003. Of the randomised participants in each trial, $0 \%$ to $52 \%$ were women, the mean age ranged from 50 to 75 years and $1 \%$ to $35 \%$ were diabetic. Between $8 \%$ and $100 \%$ had pre-existing CVD: three predominantly primary prevention/asymptomatic populations, and five predominantly secondary prevention/symptomatic populations. The difference in the proportion of people taking a statin in the randomised groups within the trial period (statin-placebo) ranged from $51 \%$ to $89 \%$. HR (or relative risk ratio estimates when HR were unknown) for all-cause mortality and CVD-specific mortality within the trial period ranged from 0.70 to 1.02 and 0.64 to 0.96 , respectively (see online supplementary eTable 1).

The post-trial follow-up ranged in mean duration from 1.6 to 15.1 years. The difference in proportion of people taking a statin in the post-trial period (for those originally randomised to statin minus those randomised to placebo) ranged from $0 \%$ to $4 \%$ (unknown for two studies). Collectively, the included studies reported on post-trial follow-up of 55732 people with 13781 deaths which occurred after the trials ended, of which 6685 were attributed to CVD. The HR (or relative risk estimates) for all-cause mortality and CVD-specific mortality ranged from 0.85 to 1.03 and 0.82 to 1.14 , respectively (see online supplementary eTable 2 ).

\section{Individual trials: comparison of within-trial and post-trial effects}

The results for CVD-specific mortality for the individual trials are presented in supplementary eTable 1 and 2 and figure 1. Of the eight included trials, the six which demonstrated significant reductions in CVD mortality within the trial period (WOSCOPS, ALERT, SSSS, PROSPER, HPS and LIPID) showed less benefit in the post-trial period than in the trial period. The two trials without significant reduction in CVD mortality within the trial period (ALLHAT-LLA and ASCOT-LLA) showed a similar lack of evidence for benefit post-trial. In only one of the eight trials was there a significant reduction in CVD mortality for the post-trial period (WOSCOPS).

The results for all-cause mortality for the individual trials are presented in online supplementary eTables 1 and 2 and figure 2. Of the eight included trials, the four which demonstrated significant reduction in all-cause mortality within the trial period (WOSCOPS, SSSS, HPS and LIPID) showed less benefit in the post-trial period than in the trial period. Three trials without a significant reduction in mortality within the trial period (ALLHAT-LLA, ALERT and PROSPER) showed a similar lack of evidence for benefit post-trial. One trial (ASCOT-LLA) without a significant reduction in mortality within the trial period demonstrated more benefit in the post-trial period. In only two of the eight trials was there a significant reduction in all-cause mortality in the post-trial period (WOSCOPS and ASCOT-LLA).

\section{Post-trial meta-analysis}

The relative risk random effect meta-analysis using posttrial data from all eight studies is presented in figure 3 (CVD mortality) and figure 4 (all-cause mortality). Although there was no evidence overall of a post-trial (legacy) effect on CVD ( $\mathrm{p}=0.15)$, there was some evidence of a legacy effect on all-cause mortality $(p=0.01)$. In the exploratory subgroup analysis, there appeared to be a difference in the post-trial (legacy) effect of statins for primary prevention compared with secondary prevention studies for both CVD and for all-cause mortality. The pooled relative risk of CVD death post-trial for those originally allocated statin compared with placebo was $0.91(0.84-0.98)$ for primary prevention trials, and 0.99 (0.94-1.05) for secondary prevention trials (permutation test $p$ value for subgroup difference $=0.15$ ) (figure 3 ). The pooled relative risk of all-cause death post-trial for those originally allocated statin compared with placebo was $0.92(0.88-0.96)$ for primary prevention trials and 0.99 $(0.95-1.03)$ for secondary prevention trials (permutation test $p$ value for subgroup difference $=0.02$ ) (figure 4 ). 
The HR meta-analysis, using post-trial data from the four studies reporting HR, is presented in figure 5 (CVD mortality) and figure 6 (all-cause mortality). Similar to the meta-analysis of relative risks, there was no definite evidence of a post-trial (legacy) effect on CVD ( $p=0.09)$, but some evidence of a legacy effect on all-cause mortality $(p=0.02)$. Pooling data from all four studies resulted in substantial heterogeneity between studies $\left(\mathrm{I}^{2}=40.7 \%\right.$ for CVD mortality and $42.3 \%$ for all-cause mortality). Restricting meta-analysis to the three primary prevention trials resulted in very low heterogeneity between studies $\left(\mathrm{I}^{2}=0.0 \%\right.$ for CVD mortality and $8.1 \%$ for all-cause mortality), and these results are presented in figure 7 (CVD mortality) and figure 8 (all-cause mortality). In the three primary prevention trials, the pooled HR for CVD death post-trial for those originally allocated statin compared with placebo was 0.87 (0.79 to $0.95, \mathrm{p}=0.003$ ), and for all-cause death, it was 0.90 ( 0.85 to $0.96, \mathrm{p}=0.001)$.

\section{DISCUSSION}

We identified eight large randomised trials which had usable post-trial data to assess legacy effects on mortality outcomes. The direct effects of the statins on mortality reduction observed during the trials were much larger than potential legacy effects observed posttrial, which suggests the rhetoric on legacy effects for statins in general may not reflect the empirical evidence. WOSCOPS was the only trial to show a possible post-trial legacy effect on all-cause and CVD-specific mortality. When we pooled data from all eight studies, we found no evidence overall of legacy effects on CVD mortality, but some evidence of possible legacy effects on all-cause mortality. In the exploratory subgroup analysis, there was some evidence of a difference in results for primary prevention compared with secondary prevention. Considering these subgroups separately, we found no evidence of legacy effects following secondary prevention trials, suggesting the importance of long-term/lifelong prevention in these patients. We found evidence of possible post-trial legacy effects only when statins were started for primary prevention-these effects were observed on both CVD mortality $(\mathrm{HR}=0.87, \mathrm{p}=0.003)$ and all-cause mortality $(\mathrm{HR}=0.90, \mathrm{p}<0.001$ ) (figure $3 \mathrm{C}, \mathrm{D})$. Participants originally randomised to placebo in two of the primary prevention trials (WOSCOPS and ASCOT-LLA) had 4\% lower rates of using a statin in the first years post-trial, which will exaggerate the estimated legacy effect (bias away from the null), but this difference is unlikely to account for all the observed post-trial benefit (whether there was a difference in statin use post-trial in ALLHAT is not known). The observed post-trial reductions in CVD and all-cause mortality may potentially represent real legacy effects of statins for populations similar to those at the time of recruitment into these studies. There may be a higher likelihood of observing legacy effects for statins when this is started for primary prevention, rather than for secondary prevention.
Our sensitive search strategy means this study is likely to have included all published follow-up reports of the major placebo-controlled statin trials, including recent follow-up reports for two of the studies (WOSCOPS and LIPID). However, we did not assess for publication bias and it is possible that unpublished follow-up reports may exist that we are unaware of. We did not assess risk of bias for the included studies, but this has been assessed by others for the original trial reports, including very recently, ${ }^{44}$ and the included studies were generally found to be high quality. Although we believe the post-trial period is the best period to analyse for detection of legacy effects, these data are no longer a randomised comparison: some patients randomised to the statin would have been saved from dying, whereas some patients in the placebo group were not. Hence, there are additional survivors in the statin group at the beginning of post-trial follow-up who are also likely to be at higher risk of CVD than survivors in the placebo group. These differences would tend to bias our results towards the null, and mean that legacy effects may be larger than we estimated. The main limitation of our report is that because our findings are based on aggregate data, we are unable to assess the effects of whether or not an individual was treated with statins during the post-trial period, and for how long, as well as their cardiovascular risk factor levels and other potential confounders. For example, although we found evidence of possible legacy effects in primary prevention, these are largely driven by WOSCOPs which was undertaken in all male participants. If there are sex-specific effects for legacy effects, it may be the fact that all participants in WOSCOPS were male, and not that they had no history of CVD, that is the more important determinant. Similarly, participants in WOSCOPS had the lowest percentage taking statins in the post-trial period out of all the studies where this was measured $(39 \%$ of active and $35 \%$ of placebo participants were taking statins at 5 years post-trial). This comparative absence of direct statin treatment effects in the post-trial period may be the more important determinant for observing a legacy effect.

We did not examine evidence of possible legacy effects on other outcomes such as non-fatal CVD, or for different post-trial follow-up times within each study, or for the same post-trial follow-up times between studies. We are aware of four other meta-analyses of data from long-term follow-up after placebo-controlled trials of lipid-lowering treatment. ${ }^{45-48}$ In three of these reports, the focus appears to have been on persistence of survival benefit, with comparison of event rates from time of randomisation, rather than post-trial legacy effect. ${ }^{45} 4748$ The other meta-analysis reported separate results for the post-trial period using data from earlier follow-up reports of six of our included trials. ${ }^{46}$ That report found evidence of posttrial reduction in CVD mortality and all-cause mortality at 2 years, and evidence for a reduction in major coronary events at both 2 years and over the total post-trial periods. The authors did not explore possible causes of 
heterogeneity for the post-trial models such as whether the primary trial was for primary or secondary prevention.

Published trial evidence supports the hypothesis that lowering cholesterol with a statin drug reduces cardiovascular events. ${ }^{49}$ Currently, the principle of using absolute risk to guide treatment decisions (as recommended by guidelines ${ }^{50-53}$ ) is that treatment is prioritised for those at highest short-term risk, and people at low short-term risk are not treated. Data on the efficacy and safety of statins has led to treatment thresholds being lowered: in the UK, the threshold was lowered from $>20 \%$ to $>10 \%$ 10-year risk of CVD; in the USA, the threshold is 10\% 10-year risk of CVD, with statins also recommended for selected patients with $7.5 \%-10 \%$ 10-year risk. ${ }^{53}$ However, as short-term risk is largely driven by age, younger people are unlikely to qualify for statins even with these lowered thresholds. For example, a recent report found that in the absence of smoking or raised blood pressure, a 10-year risk of CVD above $5 \%$ was infrequent in women younger than 50 and men younger than 40 years resident in the USA. ${ }^{54}$

Exploratory subgroup analysis in our study found evidence of possible legacy effects of statins following the primary prevention trials, which warrant further investigation. However, we note that the participants in WOSCOPS, ALLHAT and ASCOT-LLA had elevated levels of CVD risk factors (see table 1). Indeed, the majority of these people were likely to have been well above current treatment thresholds at the time of trial entry, and people with similar risk levels would now be recommended to start lifelong lipid-lowering treatment. For example, the proportion of people who had died of CVD by the end of the trial in the placebo group after 3.3 years in ASCOT, 4.8 years in ALLHAT and 4.9 years in WOSCOPS was $3 \%, 11 \%$ and $2 \%$, respectively. Legacy effects in these settings serve to emphasise the benefits of starting long-term primary prevention treatment early rather than later among people at high short-term risk. It does not provide evidence to support earlier treatment for people who have lower short-term risk than current treatment thresholds.

Advocates of early intervention argue that people who are at risk of disease in the long term, but currently displaying no symptoms or signs of disease and at low calculated short-term risk, should also be started on longterm treatment at an early age. ${ }^{518}$ But deciding when, and if, to intervene in these people is much less straightforward. The legacy effect hypothesis for statins-that the earlier you start, the lower your risk of a CVD event in the long term-has not been tested directly in an RCT comparing statins commencement at an earlier versus later age, and such a trial is unlikely to eventuate. Indirect evidence from post-trial follow-up after the large statin trials is likely the next best way to investigate this.

\section{CONCLUSION}

In this analysis of eight long-term randomised trials, we found possible post-trial legacy effects of statins on CVD mortality and all-cause mortality for primary prevention. Although the post-trial relative benefits were clearly smaller than those observed within trials, the increasing risk with age may mean that the absolute benefits are similar. Analysis of individual patient data from follow-up studies after placebo-controlled RCTs in lower-risk populations may provide more definitive evidence on whether early treatment of subclinical atherosclerosis is likely to be beneficial.

Acknowledgements We thank Colin McCowan, Chris Packard and lan Ford for providing unpublished data on events and HR for the 15-year post-trial period after WOSCOPS.

Contributors AN and LZ acquired, analysed and interpreted the data, contributed to the statistical analysis, critically revised the manuscript for important intellectual content and approved the final version. AH undertook the main statistical analysis, interpreted the data, critically revised the manuscript for important intellectual content and approved the final version. KM, PG and JD interpreted the data, critically revised the manuscript for important intellectual content and approved the final version. LI obtained funding, interpreted the data, critically revised the manuscript for important intellectual content and approved the final version. GG interpreted the data, contributed to the statistical analysis, critically revised the manuscript for important intellectual content and approved the final version. $\mathrm{KB}$ obtained funding, conceived the study and design, acquired, analysed and interpreted the data, supervised the study, drafted the manuscript and revised for important intellectual content and approved the final version. She had full access to all of the data in the study and takes responsibility for the integrity of the data and accuracy of the data analysis.

Funding The authors have not declared a specific grant for this research from any funding agency in the public, commercial or not-for-profit sectors.

Competing interests None declared.

Patient consent Not required.

Provenance and peer review Not commissioned; externally peer reviewed.

Data sharing statement All data are supplied in this publication, no additional data are available.

Open access This is an open access article distributed in accordance with the Creative Commons Attribution Non Commercial (CC BY-NC 4.0) license, which permits others to distribute, remix, adapt, build upon this work non-commercially, and license their derivative works on different terms, provided the original work is properly cited, appropriate credit is given, any changes made indicated, and the use is non-commercial. See: http://creativecommons.org/licenses/by-nc/4.0/.

\section{REFERENCES}

1. Chalmers J, Cooper ME. UKPDS and the legacy effect. $N$ Engl J Med 2008;359:1618-20.

2. Coppo R. Is a legacy effect possible in IgA nephropathy? Nephrol Dial Transplant 2013;28:1657-62.

3. Sever PS, Chang CL, Gupta AK, et al. The Anglo-Scandinavian Cardiac Outcomes Trial: 11-year mortality follow-up of the lipidlowering arm in the UK. Eur Heart J 2011;32:2525-32.

4. Ford I, Murray H, McCowan C, et al. Long-Term Safety and Efficacy of Lowering Low-Density Lipoprotein Cholesterol With Statin Therapy: 20-Year Follow-Up of West of Scotland Coronary Prevention Study. Circulation 2016;133:1073-80.

5. Robinson JG, Gidding SS. Curing atherosclerosis should be the next major cardiovascular prevention goal. J Am Coll Cardiol 2014;63:2779-85.

6. Sauser K, Levine DA, Hayward RA. A review of the clinical evidence related to early treatment of elevated LDL for cardiovascular primary prevention. Evid Based Med 2015;20:162-9.

7. Daniels SR. Prevention of atherosclerotic cardiovascular disease: what is the best approach and how early should we start? J Am Coll Cardiol 2014;63:2786-8.

8. O'Riordan M. 'Legacy Effects' of Statins: $14 \%$ Reduction in Mortality. [updated] $2011 \mathrm{http}: / /$ www.medscape.com/viewarticle/748687.

9. O'Riordan M. WOSCOPS at 20 years: study shows lifetime benefit with 5 years of statin therapy. [updated 2014 http://www.medscape. com/viewarticle/835238. 
10. Sever PS, Chang CL, Gupta AK, et al. The Anglo-Scandinavian Cardiac Outcomes Trial: 11-year mortality follow-up of the lipidlowering arm in the U.K. Eur Heart $J$ 2011;32:2525-32.

11. Palmer SC, Navaneethan SD, Craig JC, et al. HMG CoA reductase inhibitors (statins) for dialysis patients. Cochrane Database Syst Rev 2013:CD004289.

12. Palmer SC, Navaneethan SD, Craig JC, et al. HMG CoA reductase inhibitors (statins) for people with chronic kidney disease not requiring dialysis. Cochrane Database Syst Rev 2014.

13. Nozue T, Yamamoto S, Tohyama S, et al. Impacts of age on coronary atherosclerosis and vascular response to statin therapy. Heart Vessels 2014;29:456-63.

14. Packard CJ, Ford I. Long-term follow-up of lipid-lowering trials. Curr Opin Lipidol 2015;26:572-9.

15. Ridker PM, Cook NR. Cholesterol Evaluation in Young Adults: Absence of Clinical Trial Evidence Is Not a Reason to Delay Screening. Ann Intern Med 2017;166:901.

16. Expert Panel on Integrated Guidelines for Cardiovascular Health and Risk Reduction in Children and AdolescentsNational Heart, Lung, and Blood Institute. Expert panel on integrated guidelines for cardiovascular health and risk reduction in children and adolescents: summary report. Pediatrics 2011;128 Suppl 5(Suppl 5):S213-S256.

17. Goff DC, Lloyd-Jones DM, Bennett G, et al. 2013 ACC/AHA guideline on the assessment of cardiovascular risk: a report of the American College of Cardiology/American Heart Association Task Force on Practice Guidelines. J Am Coll Cardiol 20142014;63:2935-59.

18. Packard CJ, Weintraub WS, Laufs U. New metrics needed to visualize the long-term impact of early LDL-C lowering on the cardiovascular disease trajectory. Vascul Pharmacol 2015;71:37-9.

19. Mihaylova B, Emberson J, Blackwell L, et al. The effects of lowering LDL cholesterol with statin therapy in people at low risk of vascular disease: meta-analysis of individual data from 27 randomised trials. Lancet 2012;380:581-90.

20. Higgins JPT GS, 2011. Cochrane Handbook for Systematic Reviews of Interventions Version 5.1.0. [updated March 2011] http://training. cochrane.org/handbook.

21. Baigent C, Keech A, Kearney PM, et al. Efficacy and safety of cholesterol-lowering treatment: prospective meta-analysis of data from 90,056 participants in 14 randomised trials of statins. Lancet 2005;366:1267-78.

22. Higgins JP, Thompson SG. Controlling the risk of spurious findings from meta-regression. Stat Med 2004;23:1663-82.

23. UK Prospective Diabetes Study Group. Tight blood pressure control and risk of macrovascular and microvascular complications in type 2 diabetes: UKPDS 38. UK Prospective Diabetes Study Group. BMJ 1998;317:703-13.

24. Investigators GP. Results of the low-dose $(20 \mathrm{mg})$ pravastatin GISSI Prevenzione trial in 4271 patients with recent myocardial infarction: do stopped trials contribute to overall knowledge? Ital Heart J 2000;1:810-20.

25. ALLHAT Officers and Coordinators for the ALLHAT Collaborative Research Group. The Antihypertensive and Lipid-Lowering Treatment to Prevent Heart Attack Trial. Major outcomes in moderately hypercholesterolemic, hypertensive patients randomized to pravastatin vs usual care: The Antihypertensive and Lipid-Lowering Treatment to Prevent Heart Attack Trial (ALLHAT-LLT). JAMA 2002;288:2998-3007.

26. Colhoun HM, Betteridge DJ, Durrington PN, et al. Primary prevention of cardiovascular disease with atorvastatin in type 2 diabetes in the Collaborative Atorvastatin Diabetes Study (CARDS): multicentre randomised placebo-controlled trial. Lancet 2004;364:685-96.

27. Downs JR, Clearfield M, Weis S, et al. Primary prevention of acute coronary events with lovastatin in men and women with average cholesterol levels: results of AFCAPS/TexCAPS. Air Force/Texas Coronary Atherosclerosis Prevention Study. JAMA 1998;279:1615-22.

28. Fellström BC, Jardine AG, Schmieder RE, et al. Rosuvastatin and cardiovascular events in patients undergoing hemodialysis. N Engl $J$ Med 2009;360:1395-407.

29. Long-Term Intervention with Pravastatin in Ischaemic Disease (LIPID) Study Group. Prevention of cardiovascular events and death with pravastatin in patients with coronary heart disease and a broad range of initial cholesterol levels. N Engl J Med 1998;339:1349-57.

30. Holdaas H, Fellström B, Jardine AG, et al. Effect of fluvastatin on cardiac outcomes in renal transplant recipients: a multicentre, randomised, placebo-controlled trial. Lancet 2003;361:2024-31.

31. Kjekshus J, Apetrei E, Barrios V, et al. Rosuvastatin in older patients with systolic heart failure. N Engl J Med 2007;357:2248-61.

32. Knopp RH, d'Emden M, Smilde JG, et al. Efficacy and safety of atorvastatin in the prevention of cardiovascular end points in subjects with type 2 diabetes: the Atorvastatin Study for Prevention of Coronary Heart Disease Endpoints in non-insulin-dependent diabetes mellitus (ASPEN). Diabetes Care 2006;29:1478-85.

33. Koren MJ, Hunninghake DB. ALLIANCE Investigators. Clinical outcomes in managed-care patients with coronary heart disease treated aggressively in lipid-lowering disease management clinics: the alliance study. J Am Coll Cardiol 2004;44:1772-9.

34. Nakamura $\mathrm{H}$, Arakawa $\mathrm{K}$, Itakura $\mathrm{H}$, et al. Primary prevention of cardiovascular disease with pravastatin in Japan (MEGA Study): a prospective randomised controlled trial. Lancet 2006;368:1155-63.

35. Ridker PM, Danielson E, Fonseca FA, et al. Rosuvastatin to prevent vascular events in men and women with elevated C-reactive protein. N Engl J Med 2008;359:2195-207.

36. Sacks FM, Pfeffer MA, Moye LA, et al. The effect of pravastatin on coronary events after myocardial infarction in patients with average cholesterol levels. Cholesterol and Recurrent Events Trial investigators. N Engl J Med 1996;335:1001-9.

37. Randomised trial of cholesterol lowering in 4444 patients with coronary heart disease: the Scandinavian Simvastatin Survival Study (4S). Lancet 1994;344:1383-9.

38. Serruys PW, de Feyter P, Macaya C, et al. Fluvastatin for prevention of cardiac events following successful first percutaneous coronary intervention: a randomized controlled trial. JAMA 2002;287:3215-22.

39. Sever PS, Dahlöf B, Poulter NR, et al. Prevention of coronary and stroke events with atorvastatin in hypertensive patients who have average or lower-than-average cholesterol concentrations, in the Anglo-Scandinavian Cardiac Outcomes Trial-Lipid Lowering Arm (ASCOT-LLA): a multicentre randomised controlled trial. Lancet 2003;361:1149-58.

40. Shepherd J, Blauw GJ, Murphy MB, et al. Pravastatin in elderly individuals at risk of vascular disease (PROSPER): a randomised controlled trial. Lancet 2002;360:1623-30.

41. Shepherd J, Cobbe SM, Ford I, et al. Prevention of Coronary Heart Disease with Pravastatin in Men with Hypercholesterolemia. N Engl J Med Overseas Ed 1995;333:1301-8.

42. Tavazzi L, Maggioni AP, Marchioli R, et al. Effect of rosuvastatin in patients with chronic heart failure (the GISSI-HF trial): a randomised, double-blind, placebo-controlled trial. Lancet 2008;372:1231-9.

43. Wanner C, Krane V, März W, et al. Atorvastatin in patients with type 2 diabetes mellitus undergoing hemodialysis. N Engl $J$ Med 2005;353:238-48.

44. Navarese EP, Robinson JG, Kowalewski M, et al. Association between baseline Idl-c level and total and cardiovascular mortality after Idl-c lowering: A systematic review and meta-analysis. JAMA 2018;319:1566-79.

45. Kostis WJ, Moreyra AE, Cheng JQ, et al. Continuation of mortality reduction after the end of randomized therapy in clinical trials of lipid-lowering therapy. J Clin Lipidol 2011;5:97-104.

46. Lv HL, Jin DM, Liu M, et al. Long-term efficacy and safety of statin treatment beyond six years: a meta-analysis of randomized controlled trials with extended follow-up. Pharmacol Res 2014:81:64-73.

47. Fulcher J, O'Connell R, Gebski V, et al. 17765: A Meta-analysis of Outcomes at Two and Five Years After the Conclusion of Randomised Controlled Trials of Statin Therapy. Circulation 2015;132(Suppl 3):A17765.

48. Hirakawa $\mathrm{Y}$, Arima $\mathrm{H}$, Rodgers $\mathrm{A}$, et al. Cumulative in-trial and posttrial effects of blood pressure and lipid lowering: systematic review and meta-analysis. J Hypertens 2017;35:905-13.

49. Collins R, Reith C, Emberson J, et al. Interpretation of the evidence for the efficacy and safety of statin therapy. Lancet 2016;388:2532-61.

50. Stone NJ, Robinson JG, Lichtenstein AH, et al. 2013 ACC/ AHA guideline on the treatment of blood cholesterol to reduce atherosclerotic cardiovascular risk in adults: a report of the American College of Cardiology/American Heart Association Task Force on Practice Guidelines. Circulation 20142014;129(25 Suppl 2):S1-S45.

51. Therapeutic Guidelines Limited. Cardiovascular disease risk stratification- eTG Complete. Melbourne, Australia, 2016.

52. Cardiovascular Disease Risk Assessment Steering Group. Cardiovascular Disease Risk Assessment- New Zealand Primary Care Handbook 2012: New Zealand Ministry of Health, 2013.

53. National Institute for Health and Care Excellence. Cardiovascular disease: risk assessment and reduction, including lipid modification (Clinical Guideline CG 181): NICE, London. [updated Sep 2016. CG181]. https://www.nice.org.uk/guidance/CG181/chapter/1Recommendations.

54. Patel KK, Taksler GB, Hu B, et al. Prevalence of elevated cardiovascular risks in young adults: A cross-sectional analysis of national health and nutrition examination surveys. Ann Intern Med 2017;166:876. 